\title{
Hygroscopic and phase separation properties of ammonium sulfate/organics/water ternary solutions
}

\author{
M. A. Zawadowicz ${ }^{1}$, S. R. Proud ${ }^{1,2}$, S. S. Seppalainen ${ }^{1}$, and D. J. Cziczo ${ }^{1}$ \\ ${ }^{1}$ Massachusetts Institute of Technology, Cambridge, Massachusetts, USA \\ ${ }^{2}$ University of Copenhagen, Copenhagen, Denmark \\ Correspondence to: D. J. Cziczo (djcziczo@mit.edu)
}

Received: 2 January 2015 - Published in Atmos. Chem. Phys. Discuss.: 5 March 2015

Revised: 11 June 2015 - Accepted: 13 July 2015 - Published: 13 August 2015

\begin{abstract}
Atmospheric aerosol particles are often partially or completely composed of inorganic salts, such as ammonium sulfate and sodium chloride, and therefore exhibit hygroscopic properties. Many inorganic salts have well-defined deliquescence and efflorescence points at which they take up and lose water, respectively. Field measurements have shown that atmospheric aerosols are not typically pure inorganic salt, instead, they often also contain organic species. There is ample evidence from laboratory studies that suggests that mixed particles exist in a phase-separated state, with an aqueous inorganic core and organic shell. Although phase separation has not been measured in situ, there is no reason it would not also take place in the atmosphere. Here, we investigate the deliquescence and efflorescence points, phase separation and ability to exchange gas-phase components of mixed organic and inorganic aerosol using a flow tube coupled with FTIR (Fourier transform infrared) spectroscopy. Ammonium sulfate aerosol mixed with organic polyols with different $\mathrm{O}: \mathrm{C}$ ratios, including 1,4-butanediol, glycerol, 1,2,6-hexanetriol, 1,2-hexanediol, and 1,5-pentanediol have been investigated. Those constituents correspond to materials found in the atmosphere in great abundance and, therefore, particles prepared in this study should mimic atmospheric mixed-phase aerosol particles. Some results of this study tend to be in agreement with previous microscopy experiments, but others, such as phase separation properties of 1,2,6-hexanetriol, do not agree with previous work. Because the particles studied in this experiment are of a smaller size than those used in microscopy studies, the discrepancies found could be a size-related effect.
\end{abstract}

\section{Introduction}

Tropospheric aerosol particles containing organics can exist as solids or liquids with a range of viscosities, depending on temperature and relative humidity conditions. The chemical properties of those states are often radically different. For example, reactions of nitric acid with sea salt aerosols (SSA) are faster in the aqueous than in gaseous phase (Liu et al., 2008; Tolocka et al., 2004) and the oxidation of $\mathrm{N}_{2} \mathrm{O}_{5}$ proceeds readily on surfaces of liquid particles, but not solid ones (Fried et al., 1994; Hu and Abbatt, 1997; Hallquist et al., 2003; Grassian, 2001). A particle's phase can also influence its radiative properties; it has been shown that liquid particles scatter radiation more than their solid counterparts with otherwise similar chemical composition (Martin, 2000). Additionally, there is evidence that organic aerosols can be efficient CCN (cloud condensation nuclei), but also that the nature of the organics can alter the $\mathrm{CCN}$ properties (Clegg et al., 2001; Cruz and Pandis, 1998, 2000; Lambe et al., 2011; King et al., 2012). Glassy organic coatings can even change ice nucleation properties of common atmospheric inorganic particles such as mineral dust (Schill et al., 2014).

The phase transitions of pure ammonium sulfate as a result of water uptake from the gaseous phase have been wellcharacterized, but the particles in the atmosphere are rarely comprised of pure constituents. At midlatitudes, organic material contributes as much as $20-50 \%$ of the total fine aerosol mass (Parsons et al., 2006; Cruz and Pandis, 1998; Saxena et al., 1995; Zhang et al., 2007; Murphy et al., 1998). A study of several European urban and rural field sites indicated that the water-soluble fraction of fine aerosol was $65-70 \%, 20$ $50 \%$ of the total soluble aerosol material was organic and 
$70 \%$ of the total organics present in the aerosol were also polar (Zappoli et al., 1999). Russell et al. (2002) used X-ray spectromicroscopy to analyze organic coatings on SSA particles revealing a diversity of functional groups and a high degree of complexity of mixtures in those systems.

In the case of inorganic aerosol, droplets form when crystalline aerosol is exposed to humidified air. For pure salts, such as sodium chloride or ammonium sulfate, the water uptake starts rapidly within a very narrow range of relative humidity (RH). This corresponds to the deliquescence $\mathrm{RH}$ (DRH). After deliquescence, the particle enters the hygroscopic growth regime. When an aqueous particle is exposed to decreasing $\mathrm{RH}$, its water content decreases but it often does not return to zero at the DRH; instead, it experiences hysteresis in the loss of condensed phase water. The particle exists in a supersaturated aqueous state until the efflorescence RH (ERH), at which point it rapidly crystallizes to an anhydrous solid. DRH and ERH for pure ammonium sulfate have been characterized extensively at room temperature to be, respectively, 85 and $30-35 \%$, the latter with a dependence on particle volume (Liu et al., 2008; Cziczo and Abbatt, 2000; Cziczo et al., 1997). DRH and ERH do not change significantly with a decrease in temperature (Cziczo and Abbatt, 2000; Koop et al., 2000; Braban et al., 2001).

Organics were found to either suppress, enhance or have no effect on ERH and DRH of inorganic aerosol depending on the type of organic and its concentration relative to the concentration of the inorganic salt (Bertram et al., 2011; Smith et al., 2011; Parsons et al., 2006; Cruz and Pandis, 1998; Robinson et al. 2014). Organics whose O:C ratio is bigger than $\sim 0.7$, such as glycerol, were found by Bertram et al. (2011), in a study using optical microscopy, to lower the ERH and DRH of ammonium sulfate and suppress it completely at high concentrations. Efflorescence, considered a kinetic process where the free energy barrier for crystal formation must be overcome, is often described by homogeneous nucleation theory (Parsons et al., 2006). Crystalline ammonium sulfate has been shown to be a poor nucleus for subsequent heterogeneous nucleation of organics, which may serve to explain why certain organics suppress ERH of ammonium sulfate (Ciobanu et al., 2009; Parsons et al., 2006; Smith et al., 2011; Braban and Abbatt, 2004). Bertram et al. (2011) suggested that the Gibbs-Duhem relation, which implies that an increase of organic to sulfate ratio increases the chemical potential of organics but decreases the chemical potential of ammonium sulfate, explains the decrease in DRH and ERH values with the increase of organic concentration for certain organics. Thus, as the concentration of organics increases, DRH decreases to maintain unity solution saturation with respect to ammonium sulfate and ERH decreases to maintain critical supersaturation (Bertram et al., 2011).

ERH and DRH depression by certain organics, but not others, can be explained by liquid-liquid phase separation of the aerosol (Bertram et al., 2011). Phase separation oc- curs when the organic fraction of the aerosol does not fully mix with the aqueous inorganic fraction. This results in a particle whose core is predominantly aqueous and inorganic and whose outer shell is predominantly organic. Partially engulfed morphologies are also possible (Song et al., 2012; Veghte et al., 2013). Therefore, ERH for the phase-separated core of such a particle would be close to the ERH of pure ammonium sulfate (Bertram et al., 2011; Buajarern et al., 2007). For systems in which phase separation does not occur, organics disrupt the nucleation resulting in ERH/DRH depression as described above (Bertram et al., 2011; Ciobanu et al., 2009; Smith et al., 2011). According to previous studies, particles whose organic fraction has a $\mathrm{O}: \mathrm{C}$ ratio greater than $\sim 0.7$ do not undergo phase separation but those that contain organics with a $\mathrm{O}: \mathrm{C}$ ratio of less than $\sim 0.7$ do (Bertram et al., 2011; Song et al., 2012).

Ciobanu et al. (2009) studied the liquid-liquid phase separation processes in millimeter-sized droplets (12-67 $\mu \mathrm{m}$ dry diameter) composed of PEG-400 and ammonium sulfate using Raman microscopy. Based on this work, there are two distinct mechanisms of phase separation, one based on classical nucleation theory and the other based on dispersed cluster growth and coalescence (Ciobanu et al., 2009). Liquidliquid phase separation was observed for particles of all sizes investigated, but the mechanisms varied depending on particle composition (Ciobanu et al., 2009). A computer model of liquid-liquid phase separation in binary, ternary and multicomponent mixtures has been developed by Zuend et al. (2010) based on those results.

The evidence for liquid-liquid phase separation comes almost solely from microscopy (Bertram et al., 2011; You et al., 2013; Ciobanu et al., 2009) and EDB studies (Marcolli and Krieger, 2006). As a limit of the resolution, the particles studied are large, on the order of $1 \mu \mathrm{m}$ diameter or greater (Bertram et al., 2011; Ciobanu et al., 2009; Marcolli and Krieger, 2006). None of those studies have reported a dependence of phase separation on particle size, but there is now evidence from cryo-transmission electron microscopy of smaller particles that liquid-liquid phase separation is highly dependent on particle size in sub-micrometer diameter particles (Veghte et al., 2013). Veghte et al. (2013) found that for a $\left(\mathrm{NH}_{4}\right)_{2} \mathrm{SO}_{4} /$ succinic acid system, no phase separation occurred below $170 \mathrm{~nm}$; and for $\left(\mathrm{NH}_{4}\right)_{2} \mathrm{SO}_{4} /$ pimelic acid system, no phase separation occurred below $270 \mathrm{~nm}$. Additionally, there are special compounds, such as 1,2,6hexanetriol, that retain the core-shell morphology independent of particles size (M. Freedman, personal communication, 2014).

This work uses bulk spectroscopic methods to investigate phase transitions of ammonium sulfate as a result of gaseous water uptake and the impact of organic constituents. Water uptake from the gaseous phase by aerosols whose organic and inorganic constituents are phase-separated is also determined. To investigate the phase changes of sub-micrometer diameter aerosol particles, Fourier transform infrared (FTIR) 
spectroscopy in the mid-infrared (MIR) range was used because it can distinguish and quantify gas and condensedphase water (Cziczo et al., 1997). The measurements were performed on a flowing aerosol sample exposed to variable humidity air. In this manner, solid aerosols were observed to become droplets as they took up water from the gas phase (deliquescence) or liquid particles became solid as they lost water (efflorescence). Other measurement techniques that have been used to investigate aerosol-phase changes include single particle levitation coupled with spectroscopy (Raman, Mie resonance, micro-FTIR) as well as different types of microscopy on a substrate (Liu et al., 2008; Zhao et al., 2008; Parsons et al., 2006; Bertram et al., 2011). Many microscopy techniques require depositing particles on a hydrophobic slide, which represents a possible surface for heterogeneous phase transition (Liu et al., 2008; Bertram et al., 2011). Levitation techniques, such as electrodynamic balance, acoustic suspension and light pressure suspension coupled with spectroscopy are well suited for studying condensation and freezing events on single particles but not the properties of a multi-particle flow (Zhao et al., 2008; Parsons et al., 2006). The technique used in this study, FTIR coupled with a flow tube setup, can also access sizes smaller than $1 \mu \mathrm{m}$ diameter and therefore can be used to study liquid-liquid phase separation and DRH/ERH properties in small particles relevant to the atmosphere.

Because the ERH and DRH of $\left(\mathrm{NH}_{4}\right)_{2} \mathrm{SO}_{4}$ /organic/water mixtures are more complicated than of solutions devoid of organics, this study focuses on phase transitions of such ternary systems. The organic compounds used here are diols and triols, such as glycerol, 1,4-butanediol and 1,2,6hexanetriol. Refer to Table 1 for the $\mathrm{O}$ : $\mathrm{C}$ ratios of these compounds and comparison to literature-reported hygroscopic and phase-separation properties. We chose 1,2,6-hexanetriol because it is one of the special compounds whose morphology in a solution with ammonium sulfate is independent of particle size (M. Freedman, personal communication, 2014). To study the effects of phase separation on the uptake of water vapor, the particles are exposed to a flow of $\mathrm{D}_{2} \mathrm{O}$ vapor after given time to fully phase separate to investigate whether the organic layer formed on the particle surface inhibits the transfer of water vapor to the aqueous core. Based on previous results, the $\left(\mathrm{NH}_{4}\right)_{2} \mathrm{SO}_{4} /$ glycerol system in this study is the only system expected not to undergo phase separation based on its O:C ratio (Bertram et al., 2011; Song et al., 2012).

\section{Experiment}

Polydisperse droplets were generated with an atomizer. An aqueous solution of Milli-Q water $(18.2 \mathrm{M} \Omega \mathrm{cm})$ and $10 \mathrm{wt} \%$ reagent grade ammonium sulfate (99\%, Sigma Aldrich, St. Louis, MO) was used to produce inorganic aerosols. For organics, glycerol, 1,4-butanediol, 1,2,6-hexanetriol, 1,2- hexanediol, and 1,5-pentanediol were used (98\%, reagent grade, Sigma Aldrich). All pure organics were produced from $10 \mathrm{wt} \%$ solutions but the ratio of ammonium sulfate and organics in the ternary solutions was variable $(1: 1$, $1: 2$, and $1: 3$ organic/ $\left.\left(\mathrm{NH}_{4}\right)_{2} \mathrm{SO}_{4}\right)$. A custom constant output atomizer was used which had an orifice diameter of $0.030 \mathrm{~cm}$. This atomizer was designed to produce a $0.1 \mathrm{stan}-$ dard $\mathrm{L} \mathrm{min}^{-2}$ flow, which was then diluted with 0-0.9 standard $\mathrm{L} \mathrm{min}^{-2}$ dry nitrogen. The custom atomizer aerosol output was centered at $\sim 300 \mathrm{~nm}$, determined with a BMI, Inc. (Hayward, CA) differential mobility analyzer (DMA) coupled to a condensation particle counter (CPC). The scanning mobility particle sizer (SMPS) dry size distribution of particles obtained from a $10 \%$ (by weight) solution of ammonium sulfate is shown in the left panel of Fig. 1: it is a polydisperse distribution centered around $300 \mathrm{~nm}$. The dry size distribution of particles obtained from a solution containing $5 \%$ (by weight) of ammonium sulfate and $5 \%$ (by weight) of 1,2,6-hexanetriol shown in the right panel of Fig. 1 is centered around $300 \mathrm{~nm}$ as well.

For deliquescence experiments a dried aerosol flow was then mixed with a humidified nitrogen flow, which was passed through a bubbler (1.0-1.5 standard $\mathrm{L} \mathrm{min}^{-2}$; for conditions up to $80 \% \mathrm{RH}$ ) or a Nafion tube surrounded by water (for conditions to $\sim 100 \%$ ). The flow was then passed into a $9 \mathrm{~L}$ glass volume, which allowed for an $\sim 1$ min interaction time between vapor and particles and to buffer any particle production variability before moving into the flow tube in order to reduce the small-scale flux. The RH was controlled by varying the ratio of the aerosol flow, which was diluted with dry gas and passed through a dryer, and the humidified flow though the water bubbler or Nafion tube. In some experiments, described in detail later, the aerosol flow was also mixed with a nitrogen flow passed through a $\mathrm{D}_{2} \mathrm{O}$ bubbler. For measurement of efflorescence the dryer was bypassed so that the aerosol flow remained at $\sim 100 \% \mathrm{RH}$. A dry flow of gas was then added to the mixing volume to lower the $\mathrm{RH}$ with higher flows corresponding to increasingly lower $\mathrm{RH}$.

The RH was measured in two ways: with an E+E Elektronik EE08 (Engerwitzdorf, Austria) humidity/temperature sensor located at the inlet of the flow tube (Fig. 2) and by quantifying the amount of gas-phase water present in the FTIR spectra. The humidity sensor, with $\pm 1 \%$ quoted error, was verified using saturated solutions of salts with various deliquescence points, such as ammonium sulfate, sodium chloride, potassium chloride. RH was directly determined from the spectra by integrating gas-phase water lines from 1874 to $1855 \mathrm{~cm}^{-1}$. The total water vapor content obtained by integration was calibrated using the RH sensor for flows of varying $\mathrm{RH}$. The value obtained by direct integration of the FTIR spectrum is used as the $x$ axis in the figures in this paper. All experiments described here were carried out at room temperature $\left(23^{\circ} \mathrm{C} \pm 2{ }^{\circ} \mathrm{C}\right)$.

FTIR has been a valuable tool in studying model atmospheric aerosol (Cziczo et al., 1997; Cziczo and Abbatt 1999; 
Table 1. SRH (phase-separation relative humidity), ERH (efflorescence relative humidity) and DRH (deliquescence relative humidity) points for ternary systems used in this experiment. The organic to ammonium sulfate ratio was 1.0 in all cases.

\begin{tabular}{|c|c|c|c|c|c|}
\hline & $\mathrm{O}: \mathrm{C}$ & $\mathrm{SRH}$ & ERH & DRH & $\begin{array}{l}\mathrm{D}_{2} \mathrm{O} \text { vapor exchange } \\
\text { above SRH }\end{array}$ \\
\hline 1,4-butanediol & 0.5 & $\begin{array}{l}78.6-80.1 \% \text { : water activity } \\
\text { measurements, EDB (Marcolli } \\
\text { and Krieger, 2006) }\end{array}$ & $\begin{array}{l}35-40 \%: \text { FTIR/flow tube (this } \\
\text { study) }\end{array}$ & $\begin{array}{l}\text { 78-80.1\%: water activity measurements, } \\
\text { EDB, FTIR/flow tube (Marcolli and } \\
\text { Krieger, 2006; this study) }\end{array}$ & $\begin{array}{l}\text { Yes: FTIR/flow tube } \\
\text { (this study) }\end{array}$ \\
\hline glycerol & 1 & $\begin{array}{l}\text { not observed: optical mi- } \\
\text { croscopy (You et al., 2013) }\end{array}$ & $\begin{array}{l}20 \% \text { : EDB (Parsons et al., } \\
2004 \text { ) } \\
\text { not observed: FTIR/flow tube } \\
\text { (this study) }\end{array}$ & $\begin{array}{l}\text { 72-75\%: water activity measurements, } \\
\text { EDB (Marcolli and Krieger, 2006; } \\
\text { Parsons et al., 2004) } \\
\text { not observed: FTIR/flow tube (this study) }\end{array}$ & $\begin{array}{l}\text { Yes: FTIR/flow tube } \\
\text { (this study) }\end{array}$ \\
\hline 1,2,6-hexanetriol & 0.5 & $\begin{array}{l}76.7 \% \text { : optical microscopy } \\
\text { (You et al., 2013) }\end{array}$ & $\begin{array}{l}\sim 32 \% \text { : optical microscopy } \\
\text { (Bertram et al., 2011) } \\
\text { not observed: FTIR/flow tube } \\
\text { (this study) }\end{array}$ & $\begin{array}{l}\sim 80 \% \text { : optical microscopy (Bertram et } \\
\text { al., 2011) } \\
\text { not observed: FTIR/flow tube (this study) }\end{array}$ & $\begin{array}{l}\text { Yes: FTIR/flow tube } \\
\text { (this study) }\end{array}$ \\
\hline 1,2-hexanediol & 0.33 & $\begin{array}{l}79.8-94.0 \% \text { : water activity } \\
\text { measurements, EDB (Marcolli } \\
\text { and Krieger, 2006) }\end{array}$ & No data available & $\begin{array}{l}\text { 78-80.1\%: water activity measurements, } \\
\text { EDB (Marcolli and Krieger, 2006) }\end{array}$ & $\begin{array}{l}\text { Yes: FTIR/flow tube } \\
\text { (this study) }\end{array}$ \\
\hline$\left(\mathrm{NH}_{4}\right)_{2} \mathrm{SO}_{4}$ & - & - & $\begin{array}{l}\text { 31-35\%: FTIR/flow tube }(\mathrm{Cz}- \\
\text { iczo, et al. 1997; this study) }\end{array}$ & $\begin{array}{l}\text { 78-80\%: FTIR/flow tube (Cziczo, et al. } \\
\text { 1997; this study) }\end{array}$ & $\begin{array}{l}\text { Observed when liquid } \\
\text { water present on parti- } \\
\text { cle: FTIR/flow tube (this } \\
\text { study) }\end{array}$ \\
\hline
\end{tabular}
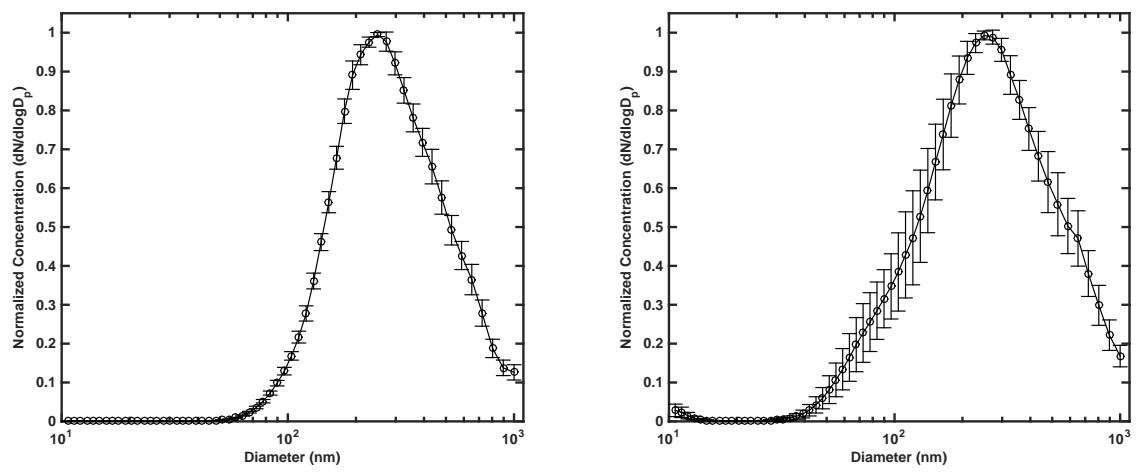

Figure 1. Size distributions measured with an SMPS for particles dispersed with the atomizer used throughout this work, dried with a silica gel dryer and mixed in a 9L mixing volume. Both distributions are the result of six SMPS scans averaged. The error bars represent the standard deviation of the scans. Left side: atomized solution of $10 \%$ ammonium sulfate. Right side: atomized solution of $5 \%$ ammonium sulfate and $5 \%$ 1,2,6-hexanetriol.

Cziczo and Abbatt 2000; Braban et al., 2003; Braban and Abbatt, 2004; Earle et al., 2010). A flow tube system coupled to an FTIR spectrometer, shown schematically in Fig. 2, was used in these studies. The flow tube was glass, $80 \mathrm{~cm}$ in length and $49 \mathrm{~mm}$ in inner diameter. Flow tube windows were $3 \mathrm{~mm}$ thick, uncoated polished ZnSe crystals. ZnSe has a nearly flat transmittance over the range or primary interest $\left(500-5000 \mathrm{~cm}^{-1)}\right.$ and is both chemically inert and non-hygroscopic. The windows were joined to the glass by EpoTek (Billerica, MA) 353ND high-performance epoxy. Windows were mounted at a slight angle, $\sim 5^{\circ}$, to prevent interference within the crystal. A Bruker (Billerica, MA) Tensor 37 FTIR spectrometer with MIR beamsplitter coupled to a liquid-nitrogen cooled external mercury cadmium telluride (MCT) detector was used to collect aerosol spectra in the range $500-8000 \mathrm{~cm}^{-1}$ at $4 \mathrm{~cm}^{-1}$ resolution. The MCT detector was enclosed in an acrylic box through which a flow of dry nitrogen was maintained at $\sim 1$ standard $\mathrm{L} \min ^{-2}$ throughout the experiment in order to minimize interference of ambient water vapor in the spectra.

FTIR spectra acquired in this experiment include absorptions from water vapor, condensed water, ammonium sulfate and alcohol (Fig. 3, Table 2). Scattering from aerosol particles is indicated by the baseline rise toward higher wavenumber. Narrow water vapor lines are centered at 3750 and $1500 \mathrm{~cm}^{-1}$. Broad condensed water bands are present at 3450,1640 , and $650 \mathrm{~cm}^{-1}$, corresponding to $\mathrm{OH}$ stretch, $\mathrm{HOH}$ bend, and $\mathrm{H}$ bonding, respectively. In Fig. 3, the $\mathrm{HOH}$ bend feature is not apparent because it coincides with the water vapor lines. The ammonium sulfate features are apparent at $2800-3300 \mathrm{~cm}^{-1}$ due to the N-H stretch mode, 1420 $1450 \mathrm{~cm}^{-1}$ due to $\mathrm{NH}_{4}^{+}$deformation mode and at 1115 and 


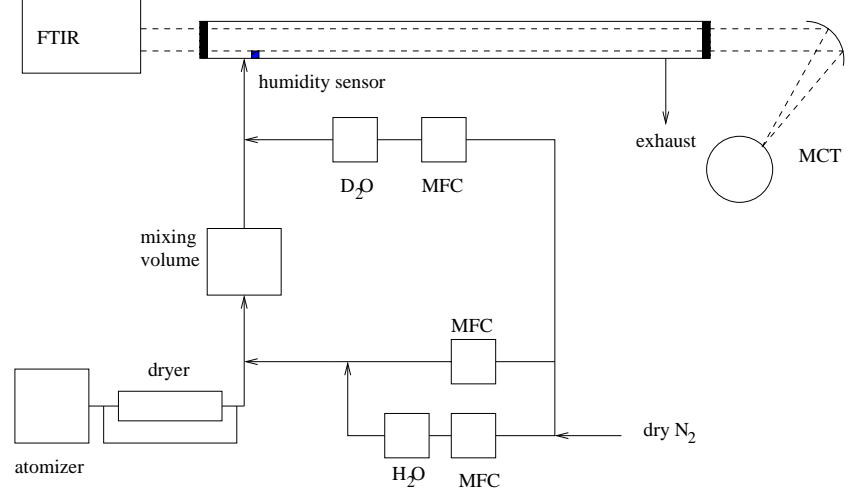

Figure 2. Experimental setup. An atomizer was used to produce particles in an aqueous or crystalline state after removal of condensed-phase water in a dryer. $\mathrm{H}_{2} \mathrm{O}$ or $\mathrm{D}_{2} \mathrm{O}$ vapor could then be added to the system from two bubblers coupled to mass flow controllers. The IR spectrum of the aerosol was then determined in a FTIR-coupled flow tube.

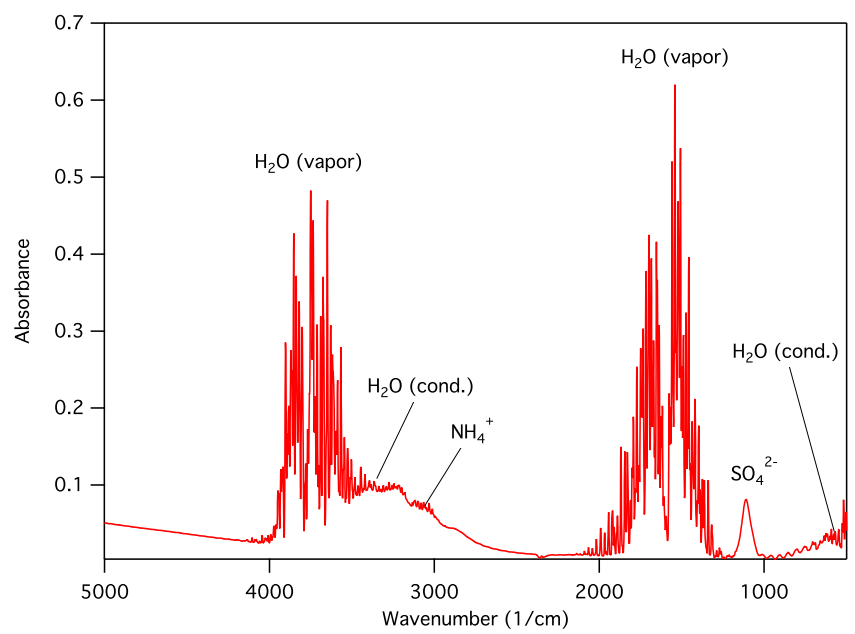

Figure 3. A typical FTIR spectrum of ammonium sulfate at high relative humidity obtained in this experiment. Note the condensed- and gas-phase features. The slope at higher wavenumber corresponds to aerosol scattering.

$620 \mathrm{~cm}^{-1}$ both due to sulfate. The $\mathrm{NH}_{4}^{+}$deformation mode is indistinguishable in the presence of the water vapor lines in Fig. 3. In Fig. 4 the gas water spectrum has been subtracted and the $\mathrm{NH}_{4}^{+}$deformation mode at $1420-1450 \mathrm{~cm}^{-1}$, as well as the $\mathrm{HOH}$ bend at $1640 \mathrm{~cm}^{-1}$ (in some spectra), are apparent. The amount of liquid-phase water was quantified by integrating the band at $1640 \mathrm{~cm}^{-1}$ after gas-phase water subtraction. Figure 4 also indicates the FTIR spectral response during an efflorescence experiment as aerosol particles uptake water: the top panel is anhydrous ammonium sulfate at $30 \% \mathrm{RH}$ and condensed-phase water features are absent. Evidence of liquid water is apparent at $60 \%$ as the condensed water spectral features. Upon dissolution, ammonium sul-
Table 2. List of IR features visible in the FTIR spectra shown in this work and corresponding central wavenumbers.

\begin{tabular}{lr}
\hline $\begin{array}{l}\text { IR } \\
\text { feature }\end{array}$ & $\begin{array}{r}\text { Central wavenumber } \\
\left(\mathrm{cm}^{-1}\right)\end{array}$ \\
\hline Water vapor & 3750 \\
Condensed water (OH stretch) & 3450 \\
$\mathrm{NH}_{4}^{+}$(N-H stretch) & 3050 \\
$\mathrm{D}_{2} \mathrm{O}$ and DOH vapor & 2700 \\
Condensed DOH & 2500 \\
Condensed water (HOH bend) & 1640 \\
Water vapor & 1500 \\
NH & 1435 \\
Sulfate & 1115 \\
Condensed water (H-bonding) & 650 \\
Sulfate & 620 \\
\hline
\end{tabular}

fate absorption bands change slightly. The $1115 \mathrm{~cm}^{-1}$ sulfate band broadens and shifts towards lower wavenumbers, and the $1420-1450 \mathrm{~cm}^{-1}$ band broadens and shifts towards higher wavenumbers. See Cziczo et al. (1997) for details.

Note that the polyols used in these experiments do not show very strong absorption bands. The $\mathrm{C}-\mathrm{H}$ and $\mathrm{O}-\mathrm{H}$ stretches are obscured by water features. Carboxylic acids, on the other hand, were found to have many strong features in the $900-1700 \mathrm{~cm}^{-1}$ region, which overlapped with water features of interest in this work. The middle panel of Fig. 4 shows the same sequence of spectra for the $\left(\mathrm{NH}_{4}\right)_{2} \mathrm{SO}_{4} / 1,2,6$-hexanetriol mixture, and the bottom panel shows spectra for the $\left(\mathrm{NH}_{4}\right)_{2} \mathrm{SO}_{4} /$ glycerol mixture. The $2800-3300 \mathrm{~cm}^{-1} \mathrm{~N}-\mathrm{H}$ stretch feature exhibits the presence of an alcohol. The $\mathrm{HOH}$ bend remains an indication of the presence of condensed-phase water in all spectra.

Phase separation is not directly observed with FTIR spectroscopy. However, gas-phase exchange of water across the organic boundary can be investigated by using $\mathrm{D}_{2} \mathrm{O}$ vapor in place of water. Figure 5 is a set of spectra produced when aerosol is exposed to $\mathrm{D}_{2} \mathrm{O}$. The spectra show aerosol from an aqueous $\left(\mathrm{NH}_{4}\right)_{2} \mathrm{SO}_{4} / 1,2,6$-hexanetriol solution in $1: 1$ ratio by mass, exposed to $\mathrm{D}_{2} \mathrm{O}$ vapor at increasing $\mathrm{RH}$ (from bottom to top). Gas-phase lines at $2600-2800 \mathrm{~cm}^{-1}$ correspond to $\mathrm{D}_{2} \mathrm{O}$ and $\mathrm{DOH}$ (Cziczo et al., 1997). The broad absorption at $2500 \mathrm{~cm}^{-1}$ corresponds to condensed-phase DOH that forms when vapor-phase $\mathrm{D}_{2} \mathrm{O}$ exchanges with liquid water in the aerosol droplets (Cziczo et al., 1997). Condensed-phase $\mathrm{DOH}$ feature grow in response to increasing concentration of $\mathrm{D}_{2} \mathrm{O}$ vapor and accessible condensed-phase $\mathrm{H}_{2} \mathrm{O}$. This growth was measured in a manner similar to the $\mathrm{HOH}$ bend proxy for condensed-phase $\mathrm{H}_{2} \mathrm{O}$, with integration of the absorption at $2500 \mathrm{~cm}^{-1}$. The amount of $\mathrm{D}_{2} \mathrm{O} / \mathrm{DOH}$ vapor can be quantified in a manner similar to the RH calibration by integrating a gas-phase line, for this work $2870-2880 \mathrm{~cm}^{-1}$. 


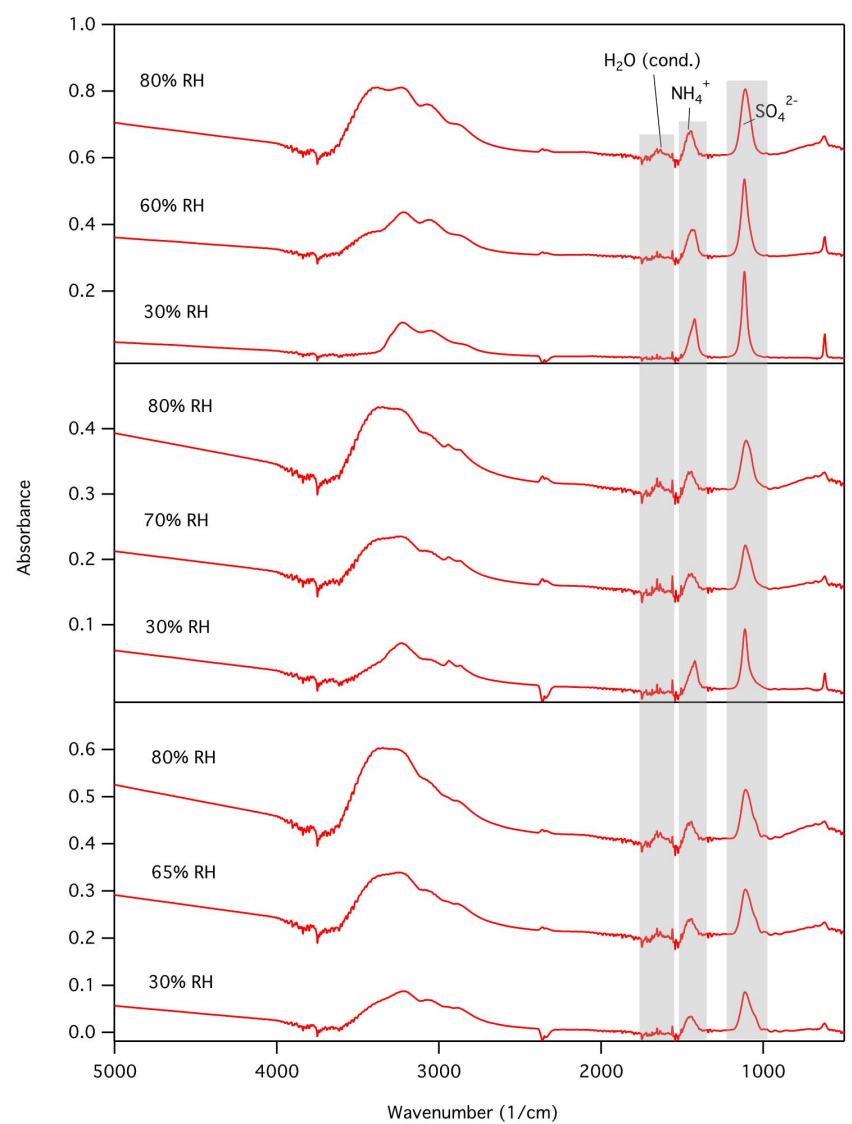

Figure 4. Spectra obtained after subtraction of gas-phase water features. Top panel: ammonium sulfate, middle panel: $1: 1$ $\left(\mathrm{NH}_{4}\right)_{2} \mathrm{SO}_{4} / 1,2,6$-hexanetriol (mixture by mass), bottom panel: $1: 1\left(\mathrm{NH}_{4}\right)_{2} \mathrm{SO}_{4} /$ glycerol. Note the presence of a condensed-phase water feature at $1640 \mathrm{~cm}^{-1}$ (the $\mathrm{HOH}$ bend). This was used to quantify liquid water in the aerosol phase.

\section{Results and discussion}

\subsection{ERH and DRH properties of ternary solutions}

Initial experiments were conducted on the binary $\left(\mathrm{NH}_{4}\right)_{2} \mathrm{SO}_{4}$ /water system to determine DRH and ERH for comparison to the literature. Experimental data of the condensed-phase water peak are plotted in the upper left panel of Fig. 6. The plotted error in the condensed water band area was quantified by averaging the deviation and noise in the $0-30 \% \mathrm{RH}$ range, where no liquid water exists, after subtraction of water vapor features, and is shown for clarity in only the left-most data point. For pure ammonium sulfate, efflorescence was observed at $35-40 \% \mathrm{RH}$ and deliquescence at $75-80 \%$, consistent with the literature (Cziczo et al., 1997).

Experiments were subsequently conducted on the more complex ternary solutions. The results of the efflorescence and deliquescence experiments on $\left(\mathrm{NH}_{4}\right)_{2} \mathrm{SO}_{4} / 1,4-$ butanediol mixtures are shown in the other panels of Fig. 6.

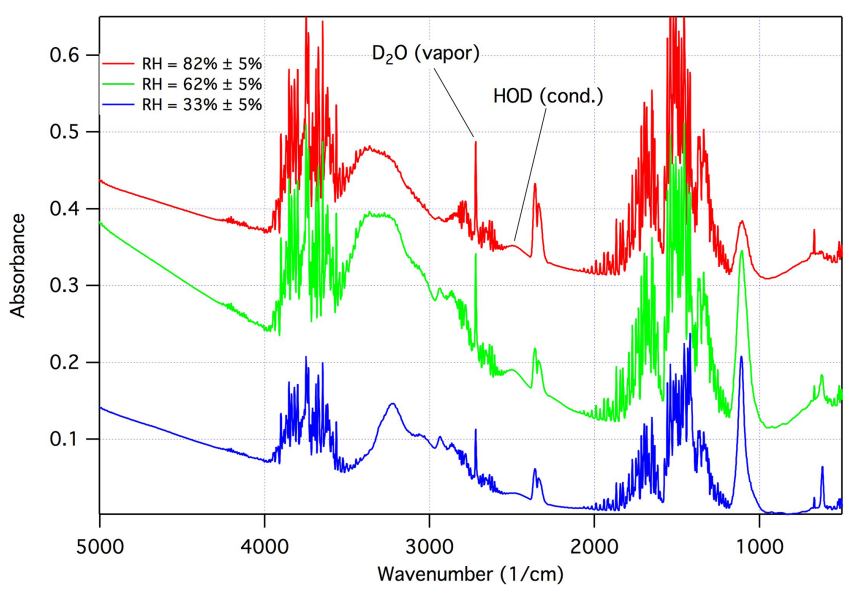

Figure 5. $\left(\mathrm{NH}_{4}\right)_{2} \mathrm{SO}_{4} / 1,2,6$-hexanetriol solution exposed to $\mathrm{D}_{2} \mathrm{O}$ at three different $\mathrm{RH}$ values. Note the presence of features related to $\mathrm{D}_{2} \mathrm{O}$ : the $\mathrm{D}_{2} \mathrm{O}$ vapor features at $2600-2800 \mathrm{~cm}^{-1}$ and the condensed HOD feature at $2500 \mathrm{~cm}^{-1}$. HOD is present in all three spectra, indicating that gas-phase diffusion occurred despite phase separation. Note that the green spectrum, taken at $62 \% \mathrm{RH}$, has a higher aerosol concentration than the other cases, resulting in the enhanced scattering slope at higher wavenumbers.

Using quantification of the $\mathrm{HOH}$ bend area, the deliquescence point was in the range of 75-80\%. This follows results of Marcolli and Krieger (2006), who showed a DRH of between 78 and $80.1 \%$ for $1: 1$ mixtures of 1,4-butanediol and $\left(\mathrm{NH}_{4}\right)_{2} \mathrm{SO}_{4}$. There is evidence of liquid water, a relatively small $\mathrm{HOH}$ feature, below the ERH of the binary $\left(\mathrm{NH}_{4}\right)_{2} \mathrm{SO}_{4}$ /water solution and the presence of the condensed phase is supported by $\mathrm{D}_{2} \mathrm{O}$ experiments, discussed in a subsequent section. According to Bertram et al. (2011), there is evidence of phase separation in these solutions. Our results indicate no or very slight inhibition of ERH due to the presence of organics.

Experiments on $\left(\mathrm{NH}_{4}\right)_{2} \mathrm{SO}_{4} /$ glycerol mixtures are detailed in Fig. 7. The presence of glycerol affects the DRH and ERH of the mixture. In the $1: 3$ glycerol $/\left(\mathrm{NH}_{4}\right)_{2} \mathrm{SO}_{4}$ solution the ERH is over the range $20-40 \%$ and the DRH is 50-70 \%; however, these transitions occur over a range of $\mathrm{RH}$ and are difficult to quantify. In the $1: 2$ glycerol/ $\left(\mathrm{NH}_{4}\right)_{2} \mathrm{SO}_{4}$ and $1: 1$ glycerol/ $\left(\mathrm{NH}_{4}\right)_{2} \mathrm{SO}_{4}$ solutions there is no evidence of a sharp efflorescence point and, consequently, a sharp deliquescence point cannot be observed. This behavior suggests no phase separation has occurred (Bertram et al., 2011). Studies that used microscopy and electrodynamic balance (EDB) methods found higher DRH for the $1: 1\left(\mathrm{NH}_{4}\right)_{2} \mathrm{SO}_{4} /$ glycerol system (72-75\%) (Marcolli and Krieger, 2006; Parsons et al., 2004). Different sizes of particles studied by those techniques could be a reason for the discrepancy.

Figure 8 contains spectra from experiments on the $\left(\mathrm{NH}_{4}\right)_{2} \mathrm{SO}_{4} / 1,2,6$-hexanetriol system. Mixtures of this sys- 

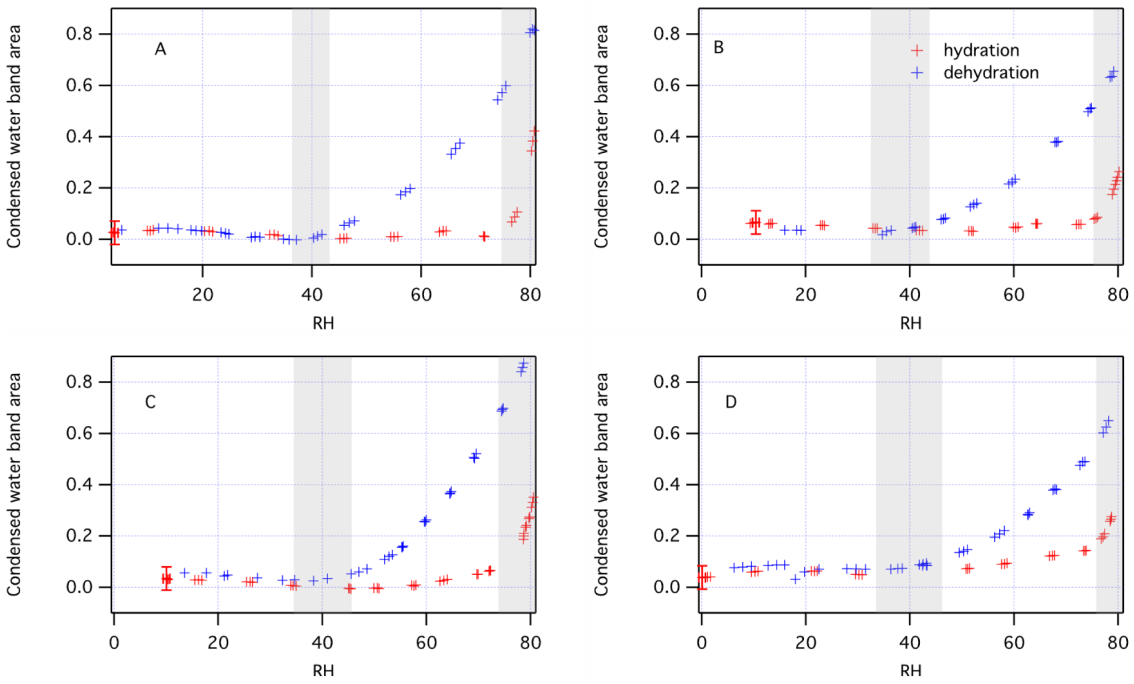

Figure 6. Deliquescence and efflorescence experiments on $\left(\mathrm{NH}_{4}\right)_{2} \mathrm{SO}_{4} / 1$,4-butanediol/water ternary mixtures of variable concentrations. (a) Pure ammonium sulfate. Note, efflorescence at $\sim 35 \% \mathrm{RH}$ and deliquescence at $\sim 80 \% \mathrm{RH}$. (b) $1: 31,4$-butanediol $/\left(\mathrm{NH}_{4}\right)_{2} \mathrm{SO}_{4}$. Note, efflorescence at 35-40\% RH and deliquescence at $80 \% \mathrm{RH}$. (c) $1: 2$ 1,4-butanediol $/\left(\mathrm{NH}_{4}\right)_{2} \mathrm{SO}_{4}$. Note, efflorescence at 35-40\% RH and deliquescence at $80 \% \mathrm{RH}$. (d) $1: 1$ 1,4-butanediol $/\left(\mathrm{NH}_{4}\right)_{2} \mathrm{SO}_{4}$. Note, efflorescence at 35-40\% $\mathrm{RH}$ and deliquescence at $80 \% \mathrm{RH}$.
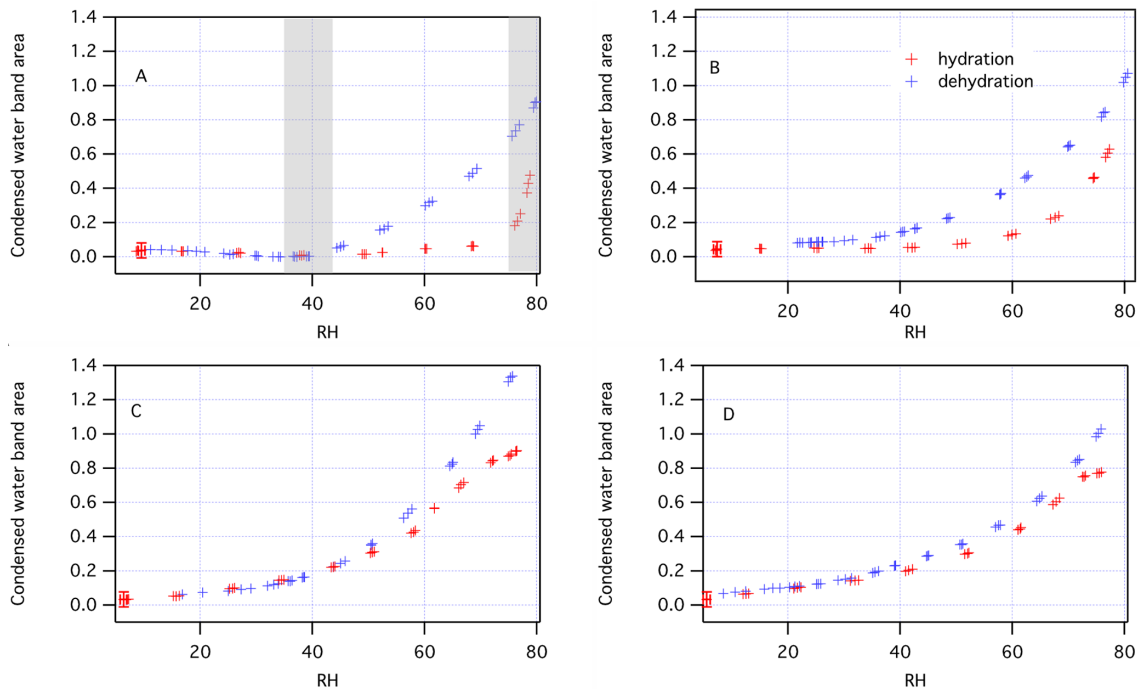

Figure 7. Deliquescence and efflorescence experiments on $\left(\mathrm{NH}_{4}\right)_{2} \mathrm{SO}_{4} /$ glycerol/water ternary mixtures of variable concentrations. (a) Pure ammonium sulfate. Note, efflorescence at $\sim 35 \% \mathrm{RH}$, deliquescence at $\sim 80 \% \mathrm{RH}$. (b) $1: 3$ glycerol $/\left(\mathrm{NH}_{4}\right)_{2} \mathrm{SO}_{4}$. Note, no clear efflorescence or deliquescence points. (c) $1: 2$ glycerol/ $\left(\mathrm{NH}_{4}\right)_{2} \mathrm{SO}_{4}$. Note, no clear efflorescence or deliquescence points (d) $1: 1$ glycerol $/\left(\mathrm{NH}_{4}\right)_{2} \mathrm{SO}_{4}$. Note, no clear efflorescence or deliquescence points.

tem again show evidence of a lack of a sharp transition during hydration and dehydration of aerosol. In the $1: 3$ 1,2,6-hexanetriol/ $\left(\mathrm{NH}_{4}\right)_{2} \mathrm{SO}_{4}$ mixture, the ERH appears unaffected by the organics but the deliquescence curve shows evidence of liquid water below $80 \% \mathrm{RH}$, until about $60 \%$ $\mathrm{RH}$. In the $1: 2$ and $1: 11,2,6$-hexanetriol/ $\left(\mathrm{NH}_{4}\right)_{2} \mathrm{SO}_{4}$ mixtures, no sharp transitions are evident during hydration (e.g., panel d). These data suggest no occurrence of phase separation in the 1,2,6-hexanetriol/ $\left(\mathrm{NH}_{4}\right)_{2} \mathrm{SO}_{4}$ mixture.
The set of experiments conducted here are listed and compared to the literature in Table 1 . The results of the efflorescence and deliquescence experiments are generally consistent with previous work that shows suppression of ERH in ternary organic/ $\left(\mathrm{NH}_{4}\right)_{2} \mathrm{SO}_{4} /$ water solutions with the extent of this effect dependent on specific organics (Bertram et al., 2011; You et al., 2013; Marcolli and Krieger, 2006). If complete or partial suppression of ERH and DRH, here evident as a lack of sharp transitions in water uptake 

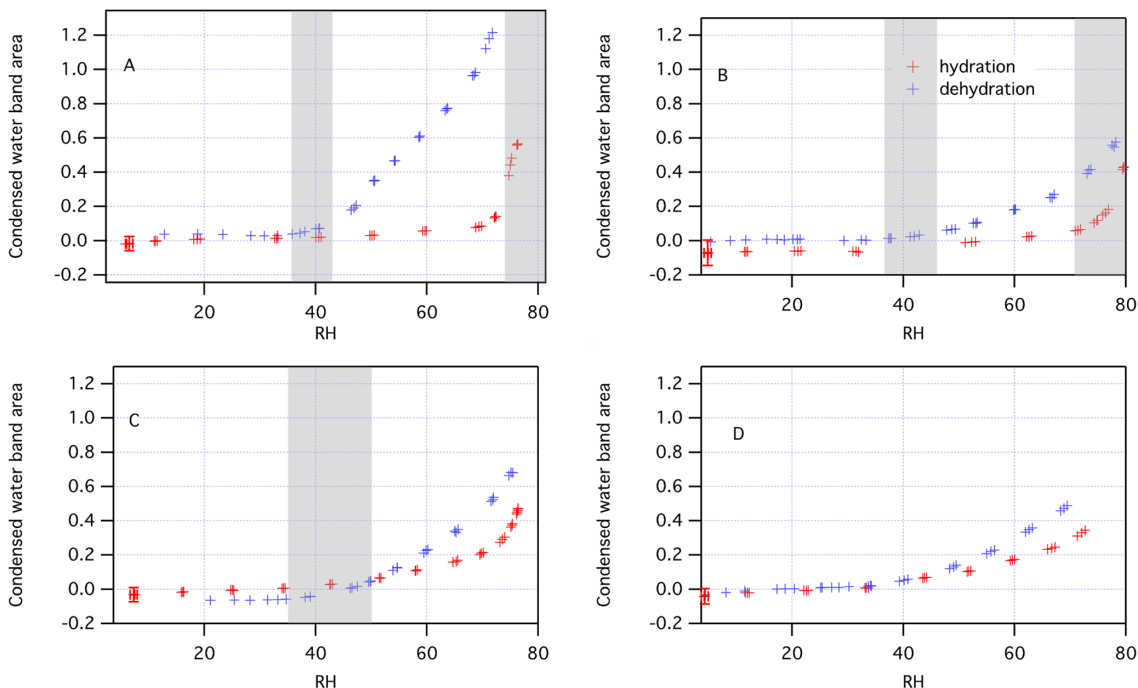

Figure 8. Deliquescence and efflorescence experiments on $\left(\mathrm{NH}_{4}\right)_{2} \mathrm{SO}_{4} / 1,2,6$-hexanetriol/water ternary mixtures of variable concentrations. (a) Pure ammonium sulfate. Note, efflorescence at $\sim 35 \% \mathrm{RH}$, deliquescence at $\sim 80 \% \mathrm{RH}$. (b) $1: 31,2,6-$ hexanetriol $/\left(\mathrm{NH}_{4}\right)_{2} \mathrm{SO}_{4}$. $\mathrm{Note}_{\text {, }}$ efflorescence at $40 \% \mathrm{RH}$, deliquescence at 70-80\% RH. (c) $1: 2$ 1,2,6-hexanetriol $/\left(\mathrm{NH}_{4}\right)_{2} \mathrm{SO}_{4}$. Note, efflorescence at 40-50\% $\mathrm{RH}$, no clear deliquescence point. (d) $1: 1$ 1,2,6-hexanetriol/ $\left(\mathrm{NH}_{4}\right)_{2} \mathrm{SO}_{4}$. Note, no clear efflorescence or deliquescence points.

by aerosols, is taken to be evidence of no phase separation, then the $\left(\mathrm{NH}_{4}\right)_{2} \mathrm{SO}_{4} /$ glycerol and $\left(\mathrm{NH}_{4}\right)_{2} \mathrm{SO}_{4} / 1,2,6$ hexanetriol systems showed no phase separation. For the $\left(\mathrm{NH}_{4}\right)_{2} \mathrm{SO}_{4}$ /glycerol system, this is consistent with the literature, as glycerol has been shown not to undergo phase separation when mixed with inorganics (Bertram et al., 2011; You et al., 2013). For the $\left(\mathrm{NH}_{4}\right)_{2} \mathrm{SO}_{4} / 1,2,6$-hexanetriol system, the data is inconsistent with the literature, as this system was shown to undergo phase separation at $76.7 \% \mathrm{RH}$ (You et al., 2013). Our data are consistent with phase separation in the $\left(\mathrm{NH}_{4}\right)_{2} \mathrm{SO}_{4} / 1,4$-butanediol system and the observed unaltered ERH and DRH points agree with previous studies (Marcolli and Krieger, 2006).

These data suggest the $\left(\mathrm{NH}_{4}\right)_{2} \mathrm{SO}_{4} /$ glycerol and $\left(\mathrm{NH}_{4}\right)_{2} \mathrm{SO}_{4} / 1,2,6$-hexanetriol systems exhibit a partial or complete suppression of ERH and DRH. This contradicts the literature for the $\left(\mathrm{NH}_{4}\right)_{2} \mathrm{SO}_{4} / 1,2,6$-hexanetriol system which does not report suppression. This result is important because it suggests potential differences between FTIR and microscopy techniques. Using electron microscopy techniques, Veghte et al. (2013) found that, for some ternary systems, sub-200 nm diameter organic/inorganic particles do not undergo phase separation. Aerosols in this size range cannot be observed by optical microscopy techniques used by Bertram et al. (2011). FTIR, however, is a bulk technique, which studies the composite aerosol within the sample volume. As described in the Experiment section, the constant output atomizer used in this work produces a polydisperse particle distribution across a wide size range shown in Fig. 1. It is therefore likely that a combination of large phase-separated and small non-phase-separated parti- cles were present in the flow tube. Indication of inhibition of ERH and DRH could have come from a subset of the overall population, in this case due to the small aerosol, as suggested by Veghte et al. (2013).

\subsection{Heterogeneous chemical potential of ternary solutions}

Cziczo et al. (1997) showed that $\mathrm{D}_{2} \mathrm{O}$ vapor remained in the gas phase when only crystalline aerosol was present, whereas gas- and condensed-phase $\mathrm{DOH}$ was rapidly formed in the presence of condensed-phase $\mathrm{H}_{2} \mathrm{O}$. For a comparison to the literature, initial experiments were conducted by adding an increasing flow of $\mathrm{D}_{2} \mathrm{O}$ vapor to a anhydrous, sub- $30 \% \mathrm{RH}$, flow of $\left(\mathrm{NH}_{4}\right)_{2} \mathrm{SO}_{4}$ aerosol (i.e., aerosol below its ERH). These data are plotted as the lower-most curve of Fig. 9 and indicate, consistent with the literature, that $\mathrm{DOH}$ is not formed in the presence of crystalline aerosol (Cziczo et al., 1997).

Using this methodology, the possible uptake of water by ternary aerosol was investigated by exposing particles to increasing concentrations of $\mathrm{D}_{2} \mathrm{O}$ in the gas phase. The formation of condensed-phase DOH in a $1: 1\left(\mathrm{NH}_{4}\right)_{2} \mathrm{SO}_{4} / 1,2,6$ hexanetriol mixture at variable RH is shown in Fig. 5. The area of the condensed-phase DOH feature is proportional to the amount of liquid water in the spectrum and, assuming a relatively constant aerosol content, it can be compared between spectra. Assuming ammonium sulfate and 1,2,6hexanetriol phase separates below $\sim 78 \% \mathrm{RH}$ (Table 1), separation should have occurred for the 30 and $60 \% \mathrm{RH}$ points (the blue and green traces in Fig. 5). The data show evidence 

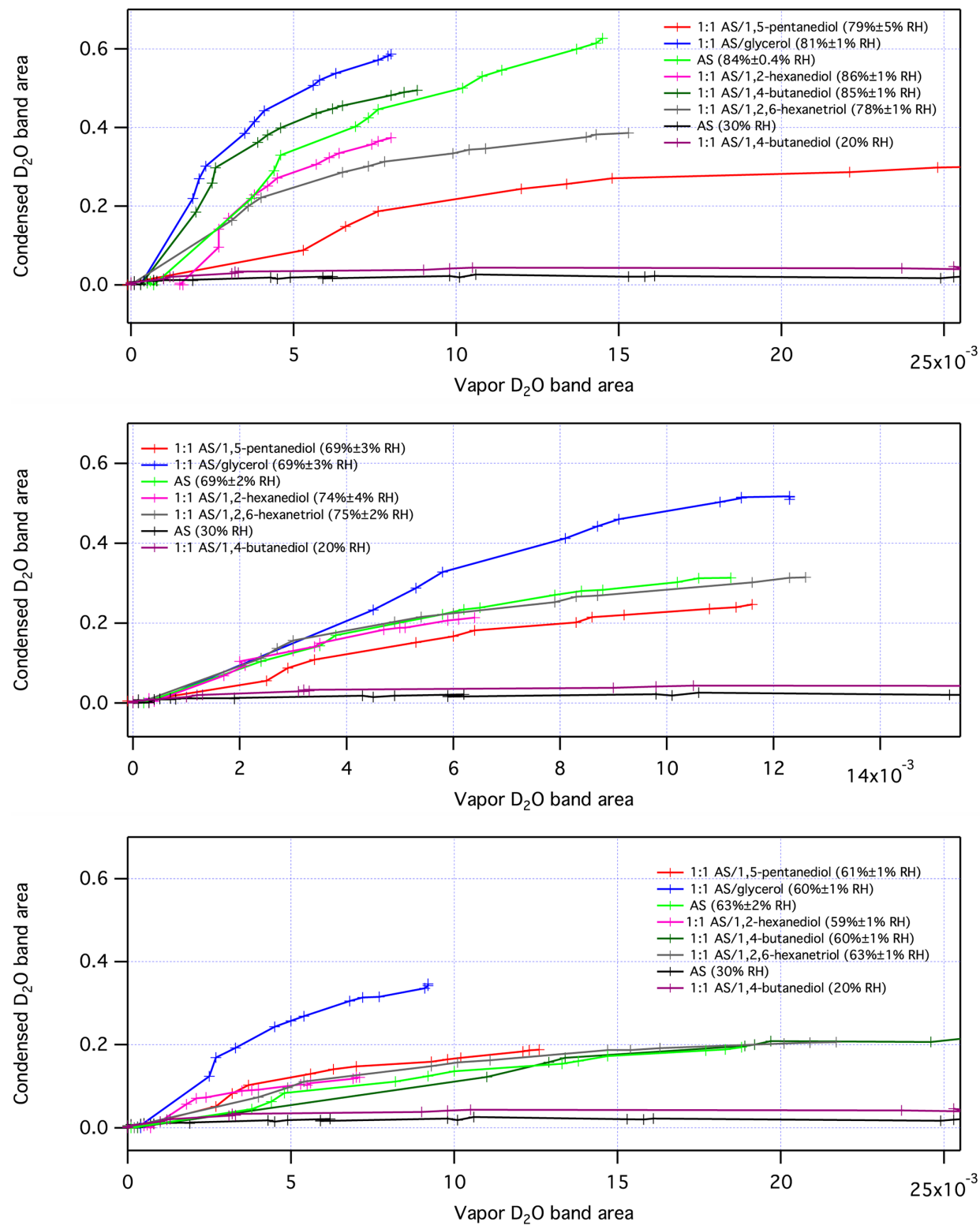

Figure 9. Gas-phase exchange experiments for organic/ $\left(\mathrm{NH}_{4}\right)_{2} \mathrm{SO}_{4}$ mixtures in three $\mathrm{RH}$ ranges. Data for pure ammonium sulfate at $30 \%$ $\mathrm{RH}$, a crystalline solid, is plotted for reference. No change in the condensed $\mathrm{D}_{2} \mathrm{O}$ band area is seen in only the two control cases: ammonium sulfate at $30 \% \mathrm{RH}$ and a $1: 1\left(\mathrm{NH}_{4}\right)_{2} \mathrm{SO}_{4} / 1$,4-butanediol mixture at $20 \% \mathrm{RH}$, both of which are below their efflorescence point (i.e., they contain no condensed-phase water). For all particles containing condensed water, an exchange of $\mathrm{D}_{2} \mathrm{O}$ vapor is apparent. Liquid-liquid phase separation does not exclude water diffusion into the aqueous core.

that DOH forms even in a system that should be phase separated.

Figure 9 is a composite plot of gas-phase exchange experiments, including the spectra in Fig. 5, on different organic/inorganic mixtures under three $\mathrm{RH}$ conditions: $80 \%$ (top), $70 \%$ (middle) and $60 \% \mathrm{RH}$ (bottom); this RH range was chosen because the organic/inorganic aerosols undergo phase separation within it (Table 1). Data for anhydrous ammonium sulfate (at $30 \% \mathrm{RH}$ ) is shown for reference in each panel. Note that a lack of $\mathrm{D}_{2} \mathrm{O}$ exchange is also exhibited by the $1: 1$ 1,4-butanediol/ $\left(\mathrm{NH}_{4}\right)_{2} \mathrm{SO}_{4}$ mixture below its efflorescence point (at $20 \% \mathrm{RH}$ ), likely indicative of a phaseseparated aerosol where the inorganic core has undergone efflorescence. These two curves, "negative control experiments", are shown for reference in all three panels.

The other organic/inorganic solutions, none of which exhibited efflorescence, show gas-phase exchange at all $\mathrm{RH}$ conditions. The intensity of the exchange signal is largest in the $\left(\mathrm{NH}_{4}\right)_{2} \mathrm{SO}_{4} /$ glycerol system, consistent with a mixture that does not phase separate or 
effloresce (i.e., liquid water is always expected to be present at the surface). Under the RH conditions studied, $\left(\mathrm{NH}_{4}\right)_{2} \mathrm{SO}_{4} / 1,4$-butanediol, $\quad\left(\mathrm{NH}_{4}\right)_{2} \mathrm{SO}_{4} / 1,2$-hexanediol, and $\left(\mathrm{NH}_{4}\right)_{2} \mathrm{SO}_{4} / 1,5$-pentanediol super-micrometer diameter particles are all expected to phase separate (Bertram et al., 2011). In these three systems sub-micrometer particles have not been studied to date and we cannot preclude that they remain in a non-phase-separated state per the finding of Veghte et al. (2013). This is a possible indication of nonphase-separated particles of small size remaining chemically active. Atmospherically, this is important because the results indicate that sub-micrometer aerosol that does not phase separate remains in a chemically active state with surface water present.

Noteworthy are the $\left(\mathrm{NH}_{4}\right)_{2} \mathrm{SO}_{4} / 1,2,6$-hexanetriol and $\left(\mathrm{NH}_{4}\right)_{2} \mathrm{SO}_{4} / 1$,4-butanediol systems which may phase separate regardless of size (M. Freedman, personal communication, 2014). The data collected here support a lack of phase separation for the former because of a lack of observed efflorescence, while the latter may phase separate since it is observed to effloresce. The data in Fig. 9 indicate that if phase separation does occur below $\sim 78 \% \mathrm{RH}$ for either system they continue to exchange $\mathrm{D}_{2} \mathrm{O}$ with the gas phase (in the case of $\left(\mathrm{NH}_{4}\right)_{2} \mathrm{SO}_{4} / 1$,4-butanediol until efflorescence of the inorganic core). Therefore, if present, an organic shell does not appear to present a barrier for vapor exchange to the core material and these particles remain chemically active.

Shorter residence time experiments were also performed. For these measurements the $9 \mathrm{~L}$ mixing volume was removed to reduce the time during which phase separation could occur, before mixing with $\mathrm{D}_{2} \mathrm{O}$, to seconds. There was no evidence of exchange stopping at the shorter residence time. This reinforces that phase separation happens on fast timescales, shorter than a second, which is expected because the diffusion of water is fast. However, organics can decrease mass accommodation of water, possibly having an influence on fast timescales (A. Bertram, personal communication, 2013). No evidence for such an effect was found.

\section{Conclusions}

This experiment examined hygroscopic properties of three mixed organic/inorganic aerosols: $\left(\mathrm{NH}_{4}\right)_{2} \mathrm{SO}_{4}$ /glycerol, $\left(\mathrm{NH}_{4}\right)_{2} \mathrm{SO}_{4} / 1,4$-butanediol and $\left(\mathrm{NH}_{4}\right)_{2} \mathrm{SO}_{4} / 1,2,6-$ hexanetriol. Liquid-liquid phase separation is expected to occur in these systems if the $\mathrm{O}: \mathrm{C}$ ratio of the organic is below $\sim 0.7$ (Bertram et al., 2011; You et al., 2013; Song et al., 2012). When liquid-liquid separation occurs, organics have no effect on hygroscopic properties and efflorescence and deliquescence of the inorganics proceeds as it would in a $\left(\mathrm{NH}_{4}\right)_{2} \mathrm{SO}_{4}$-only solution (You et al., 2013). When liquid-liquid separation does not occur, the organic can disrupt nucleation in the inorganic solution and the ERH and DRH can be inhibited (You et al., 2013). Given the
$\mathrm{O}: \mathrm{C}$ ratios used in this experiment (see Table 2), only the $\left(\mathrm{NH}_{4}\right)_{2} \mathrm{SO}_{4} /$ glycerol mixture was not expected to phase separate. ERH and DRH inhibition was observed in this system, consistent with the literature. Liquid-liquid phase separation should have occurred in the $\left(\mathrm{NH}_{4}\right)_{2} \mathrm{SO}_{4} / 1$, 4 -butanediol and $\left(\mathrm{NH}_{4}\right)_{2} \mathrm{SO}_{4} / 1,2,6$-hexanetriol mixtures. The hygroscopic behavior of the $\left(\mathrm{NH}_{4}\right)_{2} \mathrm{SO}_{4} / 1$,4-butanediol mixture did not exhibit inhibition of ERH and DRH, consistent with phase separation and the literature. The $\left(\mathrm{NH}_{4}\right)_{2} \mathrm{SO}_{4} / 1,2,6-$ hexanetriol mixture behaved like the $\left(\mathrm{NH}_{4}\right)_{2} \mathrm{SO}_{4} /$ glycerol mixture: ERH and DRH were inhibited as would be the case for a non-phase separated aerosol. This supports the observation of Veghte et al. (2013) that sub-micrometer aerosol particles do not phase separate despite the requisite $\mathrm{O}: \mathrm{C}$ ratio.

The effect of liquid-liquid phase separation on heterogeneous chemistry was also studied. The approach taken in this study was to determine water vapor exchange across the organic barrier formed on the aerosol surface in a phase-separated system. For phase separation to take place after several minutes in a mixing volume, the organic/inorganic aerosols were mixed with $\mathrm{D}_{2} \mathrm{O}$ vapor. $\mathrm{DOH}$ was produced, an indication of accessibility of the core $\mathrm{H}_{2} \mathrm{O}$, in all systems except those that had no water in them: anhydrous ammonium sulfate and $\left(\mathrm{NH}_{4}\right)_{2} \mathrm{SO}_{4} / 1,4-$ butanediol below the ERH of ammonium sulfate. The $\left(\mathrm{NH}_{4}\right)_{2} \mathrm{SO}_{4}$ /glycerol system was expected not to phase separate and the exchange observation is consistent with this phase. The $\left(\mathrm{NH}_{4}\right)_{2} \mathrm{SO}_{4} / 1$,4-butanediol, $\left(\mathrm{NH}_{4}\right)_{2} \mathrm{SO}_{4} / 1,2$ hexanediol, and $\left(\mathrm{NH}_{4}\right)_{2} \mathrm{SO}_{4} / 1$,5-pentanediol systems are expected to phase separate, at least at super-micrometer diameter sizes, and the $\left(\mathrm{NH}_{4}\right)_{2} \mathrm{SO}_{4} / 1,2,6$-hexanetriol system is expected to phase separate at all particle diameters. In these cases $\mathrm{D}_{2} \mathrm{O}$ exchange is observed in all cases. This indicates that atmospherically relevant sub-micrometer diameter particles either do not phase separate and/or an organic shell does not inhibit the exchange of vapor species such as water. In either case, organics do not appear capable of inhibiting heterogeneous chemical reactions requiring and aqueous inorganic component.

We suggest that a next step in these experiments would be to consider size-selected aerosol. This would allow for further consideration of the Veghte et al. (2013) finding that small aerosol particles $(<200 \mathrm{~nm})$ do not experience phase separation. Such experiments would require increased sensitivity to the lower aerosol concentrations required when only a size-selected portion of the population is used.

Acknowledgements. This work was supported by a NASA Earth and Space Science Fellowship, NASA grant NNX13AO15G and NOAA grant NA11OAR4310159. The authors would like to thank Allan K. Bertram and Miriam A. Freedman for useful discussions.

Edited by: B. Ervens 


\section{References}

Bertram, A. K., Martin, S. T., Hanna, S. J., Smith, M. L., Bodsworth, A., Chen, Q., Kuwata, M., Liu, A., You, Y., and Zorn, S. R.: Predicting the relative humidities of liquid-liquid phase separation, efflorescence, and deliquescence of mixed particles of ammonium sulfate, organic material, and water using the organic-to-sulfate mass ratio of the particle and the oxygen-tocarbon elemental ratio of the organic component, Atmos. Chem. Phys., 11, 10995-11006, doi:10.5194/acp-11-10995-2011, 2011.

Braban, C. F. and Abbatt, J. P. D.: A study of the phase transition behavior of internally mixed ammonium sulfate - malonic acid aerosols, Atmos. Chem. Phys., 4, 1451-1459, doi:10.5194/acp4-1451-2004, 2004.

Braban, C. F., Abbatt, J. P. D., and Cziczo, D. J.: Deliquescence of Ammonium Sulfate Particles at Sub-Eutectic Temperatures, Geophys. Res. Lett., 28, 3879-3882, 2001.

Braban, C. F., Carroll, M. F., Styler, S. A., and Abbatt, J. P. D.: Phase transitions of malonic and oxalic acid aerosols, J. Phys. Chem. A, 107, 6594-6602, 2003.

Buajarern, J., Mitchem, L., and Reid, J. P.: Characterizing multiphase organic/inorganic/aqueous aerosol droplets, J. Phys. Chem. A, 111, 9054-9061, 2007.

Ciobanu, V. G., Marcolli, C., Krieger, U. K., Weers, U., and Peter, T.: Liquid-liquid phase separation in mixed organic/inorganic aerosol particles, J. Phys. Chem. A, 113, 10966-10978, 2009.

Clegg, S. L., Seinfeld, J. H., and Brimblecombe, P.: Thermodynamic modeling of aqueous aerosols containing electrolytes and dissolved organic compounds, J. Aerosol Sci., 32, 713-738, 2001.

Cruz, C. N. and Pandis, S. N.: The effect of organic coatings on the cloud condensation nuclei activation of inorganic atmospheric aerosol, J. Geophys. Res., 103, 13111-13123, 1998.

Cruz, C. N. and Pandis, S. N.: Deliquescence and hygroscopic growth of mixed inorganic-organic atmospheric aerosol, Environ. Sci. Technol., 34, 4313-4319, 2000.

Cziczo, D. J. and Abbatt, J. P. D.: Deliquescence, efflorescence, and supercooling of ammonium sulfate aerosols at low temperature: Implications for cirrus cloud formation and aerosol phase in the atmosphere, J. Geophys. Res., 104, 13781-13790, 1999.

Cziczo, D. J. and Abbatt, J. P. D.: Infrared observations of the response of $\mathrm{NaCl}, \mathrm{MgCl} 2, \mathrm{NH}_{4} \mathrm{HSO}_{4}$ and $\mathrm{NH}_{4} \mathrm{NO}_{3}$ aerosols to changes in relative humidity from 298 to 238 K, J. Phys. Chem. A, 104, 2038-2047, 2000.

Cziczo, D. J., Nowak, J. B., Hu, J. H., and Abbatt, J. P. D.: Infrared spectroscopy of model tropospheric aerosols as a function of relative humidity: Observation of deliquescence and crystallization, J. Geophys. Res., 102, 18843-18850, 1997.

Earle, M. E., Kuhn, T., Khalizov, A. F., and Sloan, J. J.: Volume nucleation rates for homogeneous freezing in supercooled water microdroplets: results from a combined experimental and modelling approach, Atmos. Chem. Phys., 10, 7945-7961, doi:10.5194/acp-10-7945-2010, 2010.

Fried, A., Henry, B. E., and Calvert, J. G.: The reaction probability of $\mathrm{N} 2 \mathrm{O} 5$ with sulfuric acid aerosols at stratospheric temperatures and compositions, J. Geophys. Res., 99, 3517-3532, 1994.

Grassian, V. H.: Heterogeneous uptake and reaction of nitrogen oxides and volatile organic compounds on the surface of atmospheric particles including oxides, carbonates, soot and mineral dust: Implications for the chemical balance of the troposphere, Int. Rev. Phys. Chem., 20, 467-548, 2001.

Hallquist, M., Stewart, D. J., Stephenson, S. K., and Cox, R. A.: Hydrolysis of $\mathrm{N}_{2} \mathrm{O}_{5}$ on sub-micron sulfate aerosols, Phys. Chem. Chem. Phys., 5, 3453-3463, 2003.

$\mathrm{Hu}$, J. H. and Abbatt, J. P. D.: Reaction probabilities for $\mathrm{N}_{2} \mathrm{O}_{5}$ hydrolysis on sulfuric acid and ammonium sulfate aerosols at room temperature, J. Phys. Chem. A, 101, 871-878, 1997.

Lambe, A. T., Onasch, T. B., Massoli, P., Croasdale, D. R., Wright, J. P., Ahern, A. T., Williams, L. R., Worsnop, D. R., Brune, W. H., and Davidovits, P.: Laboratory studies of the chemical composition and cloud condensation nuclei (CCN) activity of secondary organic aerosol (SOA) and oxidized primary organic aerosol (OPOA), Atmos. Chem. Phys., 11, 8913-8928, doi:10.5194/acp11-8913-2011, 2011.

King, S. M., Butcher, A. C., Rosenoern, T., Coz, E., Lieke, K. I., de Leeuw, G., Nilsson, E. D., and Bilde, M.: Investigating Primary Marine Aerosol Properties: CCN Activity of Sea Salt and Mixed Inorganic-Organic Particles, Environ. Sci. Technol., 46, 1040510412, 2012.

Koop, T., Kapilashrami, A., Molina, L. T., and Molina, M. J.: Phase transitions of sea- salt/water mixtures at low temperatures: Implications for ozone chemistry in the polar marine boundary layer, J. Geophys. Res., 105, 26393-26402, 2000.

Liu, Y., Yang, Z., Desyaterik, Y., Gassman, P. L., Wang, H., and Laskin, A.: Hygroscopic behavior of substrate-deposited particles studied by micro-FT-IR spectroscopy and complementary methods of particle analysis, Anal. Chem., 80, 633-642, 2008.

Marcolli, C. and Krieger, U. K.: Phase changes during hygroscopic cycles of mixed organic/inorganic model systems of tropospheric aerosols, J. Phys. Chem. A, 110, 1881-1893, 2006.

Martin, S. T.: Phase transitions of aqueous atmospheric particles, Chem. Rev., 100, 3403-3453, 2000.

Murphy, D. M., Thomson, D. S., Middlebrook, A. M., and Schein, M. E.: In situ single-particle characterization at Cape Grim, J. Geophys. Res., 103, 16485-16491, 1998.

Parsons, M. T., Knopf, D. A., and Bertram, A. K.: Deliquescence and crystallization of ammonium sulfate particles internally mixed with water-soluble organic compounds, J. Phys. Chem. A, 108, 11600-11608, 2004.

Parsons, M. T., Riffell, J. L., and Bertram, A. K.: Crystallization of aqueous inorganic-malonic acid particles: Nucleation rates, dependence on size and dependence on the ammonium-to-sulfate ratio, J. Phys. Chem. A, 110, 8101-8115, 2006.

Robinson, C. B., Schill, G. P., and Tolbert, M. A.: Optical growth of highly viscous organic/sulfate particles, J. Atmos. Chem., 71, 145-156, 2014.

Saxena, P., Hildemann, L. M., McMurry, P. H., and Seinfeld, J. H.: Organics alter hygroscopic behavior of atmospheric particles, J. Geophys. Res., 100, 18755-18770, 1995.

Schill, G. P., De Haan, D. O., and Tolbert, M. A.: Heterogeneous ice nucleation on simulated secondary organic aerosol, Environ. Sci. Technol., 48, 1675-1682, 2014.

Smith, M. L., Kuwata, M., and Martin, S. T.: Secondary organic material produced by the dark ozonolysis of $\alpha$-pinene minimally affects the deliquescence and efflorescence of ammonium sulfate, Aerosol Sci. Technol., 45, 244-261, 2011.

Song, M., Marcolli, C., Krieger, U. K., Zuend, A., and Peter, T.: Liquid-liquid phase separation in aerosol particles: Dependence 
on $\mathrm{O}: \mathrm{C}$, organic functionalities, and compositional complexity, Geophys. Res. Lett., 39, L19801, doi:10.1029/2012GL052807, 2012.

Tolocka, M. P., Saul, T. D., and Johnston, M. V.: Reactive uptake of nitric acid into aqueous sodium chloride droplets using realtime single-particle mass spectrometry, J. Phys. Chem. A, 108, 2659-2665, 2004.

Veghte, D. P., Altaf, M. B., and Freedman, M. A.: Size dependence of the structure of organic aerosol, J. Amer. Chem. Soc., 135, 16 046-16 049, 2013.

You, Y., Renbaum-Wolff, L., and Bertram, A. K.: Liquid-liquid phase separation in particles containing organics mixed with ammonium sulfate, ammonium bisulfate, ammonium nitrate or sodium chloride, Atmos. Chem. Phys., 13, 11723-11734, doi:10.5194/acp-13-11723-2013, 2013.

Zappoli, S., Andracchio, A., Fuzzi, S., Facchini, M. C., Gelencsér, A., Kiss, G., Krivácsy, Z., Molnár, Á., Mészáros, E., Hansson, H.-C., Rosman, K., and Zebühr, Y.: Inorganic, organic and macromolecular components of fine aerosol in different areas of Europe in relation to their water solubility, Atmos. Environ., 33, 2733-2743, 1999.
Zhang, Q., Jimenez, J. L., Canagaratna, M. R., Allan, J. D., Coe, H., Ulbrich, I., Alfarra, M. R., Takami, A., Middlebrook, A. M., Sun, Y. L., Dzepina, K., Dunlea, E., Docherty, K., DeCarlo, P. F., Salcedo, D., Onasch, T., Jayne, J. T., Miyoshi, T., Shimono, A., Hatakeyama, S., Takegawa, N., Kondo, Y., Schneider, J., Drewnick, F., Borrmann, S., Weimer, S., Demerjian, K., Williams, P., Bower, K., Bahreini, R., Cottrell, L., Griffin, R. J., Rautiainen, J., Sun, J. Y., Zhang, Y. M., and Worsnop, D. R.: Ubiquity and dominance of oxygenated species in organic aerosols in anthropogenically-influenced Northern Hemisphere midlatitudes, Geophys. Res. Lett., 34, L13801, doi:10.1029/2007GL029979, 2007.

Zhao, L., Wang, F., Zhang, K., Zeng, Q., and Zhang Y.: Deliquescence and efflorescence processes of aerosol particles studied by in situ FTIR and Raman spectroscopy, Chin. J. Chem. Phys., 21, $1-11,2008$.

Zuend, A., Marcolli, C., Peter, T., and Seinfeld, J. H.: Computation of liquid-liquid equilibria and phase stabilities: implications for RH-dependent gas/particle partitioning of organic-inorganic aerosols, Atmos. Chem. Phys., 10, 7795-7820, doi:10.5194/acp10-7795-2010, 2010. 